\title{
ADDITIVE MANUFACTURING OF METAL PRODUCTS (REVIEW)
}

\author{
V.V. ZHUKOV, G.M. GRIGORENKO and V.A. SHAPOVALOV \\ E.O. Paton Electric Welding Institute, NASU \\ 11 Kazimir Malevich Str., 03680, Kiev, Ukraine. E-mail: office@paton.kiev.ua
}

\begin{abstract}
Different characteristics of methods of additive manufacturing of metal products were considered. The prospects of technologies using metal wire as a consumable material were noted. The current state of research works in the field of additive manufacturing of layer-by-layer electric arc volumetric surfacing was shown. 20 Ref., 3 Tables, 10 Figures.
\end{abstract}

Ke y w ord s : additive manufacturing, prototyping, shape formation and structure control, laser surfacing using consumable wire, freeform fabrication using electron beam, electric arc volumetric layer-by-layer surfacing

The term «additive manufacturing» (AM) is used to define a group of technological methods of rapid prototyping, which allow creating solid, 3D products of different materials according to 3D computer model [1]. ASTM F2792-12A Standard provides definition to the term $\mathrm{AM}$ as the «method of joining materials, at which layer-by-layer creation of the object according to the preset digital three-dimensional model occurs». The first AM methods, which appeared in the early 1980s, were mainly specialized in manufacture of products of polymer plastics and rubbers. At present, these methods found a successful commercial application in such fields as aerospace production, mechanical engineering, medicine, architecture and design, consumer electronics, jewelry production and military industry [2-5]. Along with the development of AM methods using polymeric materials as consumables, the methods were also developed using metal alloys.

The possibility of manufacturing metal product of a final shape or a shape close to final one within a one technological operation is seen challenging in the field of direct manufacturing. The conventional field of application of manufacturing method at the other equal conditions can be represented as a dependence of form complexity on number of products. Figure 1 represents the area of AM application in the field of metallurgical manufacturing [6]. AM methods can be competitive if it is necessary to manufacture a small number of products or parts of complex shapes, or products with the specified structure.

As compared to classical methods of manufacturing (including machining on milling machine-tools with computer control (CNC), AM methods have certain advantages like:
- possibility of full automation of the process of product designing (including the stage of designing a digital 3D model), which reduces the number of manhours required for fabrication of product, and reduces the total time of fabrication in general;

- competitiveness of AM methods application for manufacture of products of expensive titanium and nickel alloys because of the low coefficient of material consumption. This advantage is especially important in the aerospace industry and manufacture of parts, which are often characterized by high coefficients of material consumption (Figure 2).

In Table 1 different AM methods are shown, grouped according to standard ASTM F2792. This standard assumes subdividing the AM methods in the field of manufacturing metal products according to the used principle based on melting (sintering) of powder bed; based on binder injection on the powder bed; based on surfacing using concentrated power source; based on laminating of sheet metal material.

It should be noted that the majority of methods were patented in the 1990s in connection with expi-

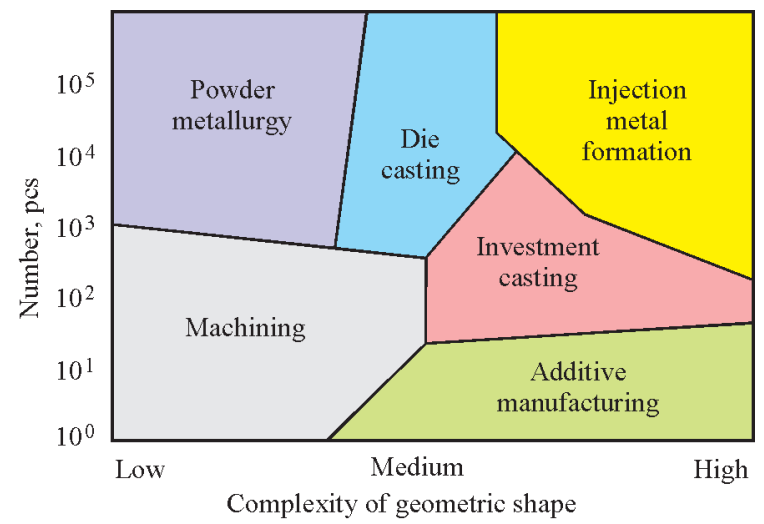

Figure 1. Quality position of AM application area relatively to the widespread methods of manufacturing [6] 


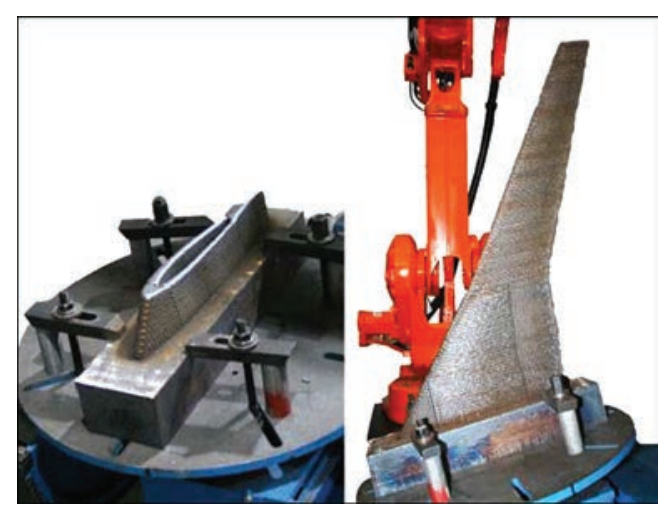

Figure 2. Model of wing designed according to WAAM technology [7]

ration of patents $[3,8]$, many variants of one and the same method appear. In Table 1 the names of methods most cited in the literature are given.

The methods of additive manufacturing of metal products have distinctive features. In Table 2 the comparison of some technological characteristics of different AM methods is presented.

The methods using powder as a consumable material are introduced wider at the moment as compared to the methods using wire as a consumable material due to the possibility of manufacturing products at a high geometric accuracy. In addition, the methods using metal powder allow producing products of powder metallic compositions, which is inherent to powder metallurgy. However, the efficiency of powder AM methods is very low, which is estimated by tens of grams per minute, which limits the possibility of their application for manufacture of large-sized products. In addition, the need in protection chamber and peculiarities of transportation and storage of metal powder
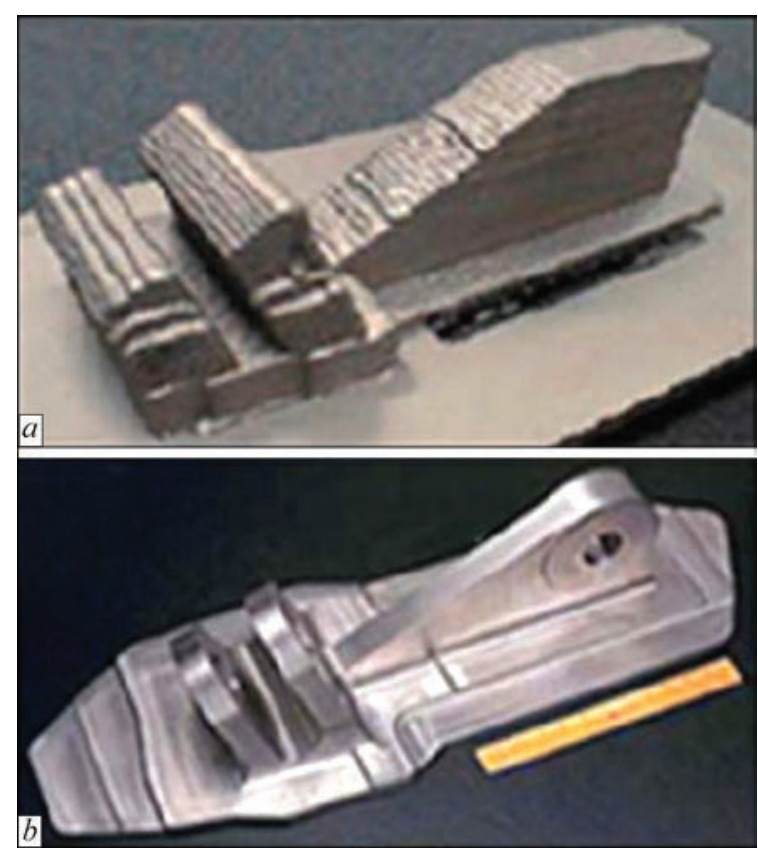

Figure 3. Semi-product $(a)$ of part $(b)$ manufactured by WFLB method

materials impose certain difficulties on application of powder AM methods. Laser engineered net shaping and the similar methods, using the principle of deposition by metal powder supplied in a jet of shielding gas to the area of laser beam action, although do not require the protective chamber for surfacing, nevertheless, because of spilling the powder, they require isolation of working area and individual protection for service personnel $[6,13]$.

AM methods using wire as a consumable material, as compared to powder AM methods possess $100 \%$ efficiency of material use, as well as significantly

Table 1. Classification of AM methods according to the used principle

\begin{tabular}{|c|c|c|}
\hline Principle & Name of method/original name & Consumable material \\
\hline \multirow{3}{*}{ Fusion of powder bed } & Selective laser sintering (SLS) [9] & \multirow{3}{*}{ Metallic powder } \\
\cline { 2 - 2 } & Selective laser melting (SLM) [10] & \\
\cline { 2 - 2 } & Electron beam melting (EBM) [11] & \multirow{2}{*}{ Wire } \\
\hline Injection of binder on powder bed & Powder bed and inkjet 3D printing (3DP) [12] & \\
\cline { 2 - 3 } Surfacing using concentrated power & Laser engineered net shaping (LENS) [13] & Sheet metal, foil \\
\cline { 2 - 3 } source & Wire fed laser beam (WFLB) [14] & \\
\cline { 2 - 3 } & Electron beam freeform fabrication (EBF $)[15]$ & \\
\cline { 2 - 3 } & Wire and arc additive manufacturing (WAAM) [16] & \\
\hline Lamination of metal sheets & Ultrasonic additive manufacturing (UAM) [17] & \\
\hline
\end{tabular}

Table 2. Technological characteristics of some AM methods [6]

\begin{tabular}{|c|c|c|c|c|c|}
\hline $\begin{array}{l}\text { Used } \\
\text { material }\end{array}$ & Name of method & $\begin{array}{l}\text { Height of deposited } \\
\text { layer, } \mu \mathrm{m}\end{array}$ & $\begin{array}{l}\text { Surfacing } \\
\text { rate, } g / \text { min }\end{array}$ & $\begin{array}{c}\text { Accuracy } \\
\text { of performance, mm }\end{array}$ & $\begin{array}{c}\text { Surface } \\
\text { roughness, } \mu \mathrm{m}\end{array}$ \\
\hline \multirow{4}{*}{ Powder } & $\mathrm{LC}^{*}$ & - & $1-30$ & $( \pm 0.025)-( \pm 0.069)$ & $1-2$ \\
\hline & SLM & $20-100$ & & \pm 0.04 & $9-10$ \\
\hline & SLS & 75 & $\sim 0.1$ & \pm 0.05 & $14-16$ \\
\hline & DLF $^{*}$ & 200 & 10 & \pm 0.13 & $\sim 20$ \\
\hline \multirow{2}{*}{ Wire } & WAAM & $\sim 1500$ & 12 & \pm 0.2 & 200 \\
\hline & $\mathrm{EBF}_{3}$ & - & Up to 330 & Low & High \\
\hline
\end{tabular}


Table 3. Results of mechanical tests of metal produced using electric arc additive surfacing

\begin{tabular}{|l|c|c|}
\hline $\begin{array}{c}\text { Orientation of specimen } \\
\text { cutting out }\end{array}$ & $\begin{array}{c}\text { Tensile } \\
\text { strength, MPa }\end{array}$ & Elongation, \% \\
\hline Vertical & 489 & 35.0 \\
\hline Horizontal (top) & 484 & 22.5 \\
\hline Horizontal (bottom) & 499 & 33.1 \\
\hline
\end{tabular}

higher mass productivity, which justifies the application of methods for creating large-sized products. Despite the low accuracy and rough surface, the methods using wire as a consumable material, allow producing semi-products at considerable saving of material at the subsequent stages of treatment (Figure 3).

During investigation of metal of products manufactured according to the AM technologies using wire and powder [6] the similarity of microstructure of the specimens, manufactured using different methods, was noted. Nevertheless, the presence of some porosity in the metal of products manufactured according to AM technology using consumable powder was noted.

AM methods, using wire as a consumable material, depending on the concentrated power source can be divided into laser, electron beam and electric arc. It is noted [14] that laser AM methods are characterized by a high accuracy as compared to other methods using wire. Nevertheless, the laser methods of volumetric surfacing have low (2-5\%) power efficiency. The methods of electron beam additive surfacing possess the much higher power efficiency (15-20\%), but initially the method of electron beam surfacing of metallic freeforms was developed in NASA for challenging application in space [15] and requires using the equipment to create a vacuum environment. Accordingly, the size of parts produced by the electron beam surfacing using wire is limited by the size of the vacuum chamber (taking into account the equipment placed in it). Moreover, the need in operation with vacuum equipment imposes certain difficulties in the application of the method.

As compared to laser and electron beam surfacing, electric arc surfacing of freeforms involving the

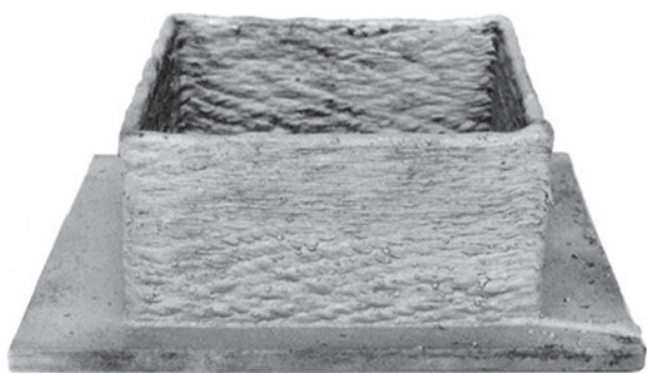

Figure 4. Experimental product manufactured using method of electric arc additive surfacing

methods of electric arc welding using consumable or non-consumable electrode in shielding gas has significant power efficiency. Some methods of TIG or MIG welding can reach the power efficiency of up to $90 \%$ [6]. Nevertheless, all the AM methods using wire possess a number of common features, such as residual stresses and deformations of a product caused by intensive heating, relatively low accuracy of fabrication and characteristic «staged» surface.

However, AM methods using wire and, in particular, the methods of electric arc AM remain a challenging and developing area of metallurgical manufacturing [8]. At the moment, there are relatively few publications devoted to the AM problem based on arc welding technology. And though the first articles devoted to electric arc additive surfacing appeared in the 1990s $[3,18]$, the problem of weld metal structure formation, and the problems associated with weld shaping under the non-stationary conditions of heat dissipation remain unsolved and relevant $[15,19]$.

Using method of electric arc welding already in 1992 the researchers of the Nottingham University fabricated a volumetric product of the rectangular box type (Figure 4) of steel of the following composition: wt.\%: $0.08 \mathrm{C}, 0.9 \mathrm{Si}, 1.5 \mathrm{Mn}$. The height of the product wall was $100 \mathrm{~mm}$, and it was manufactured in 70 welding passes.

The analysis of mechanical characteristics of the produced metal showed a slight discrepancy during tensile testing of the specimens, cut along and across the welding direction (Table 3 ).

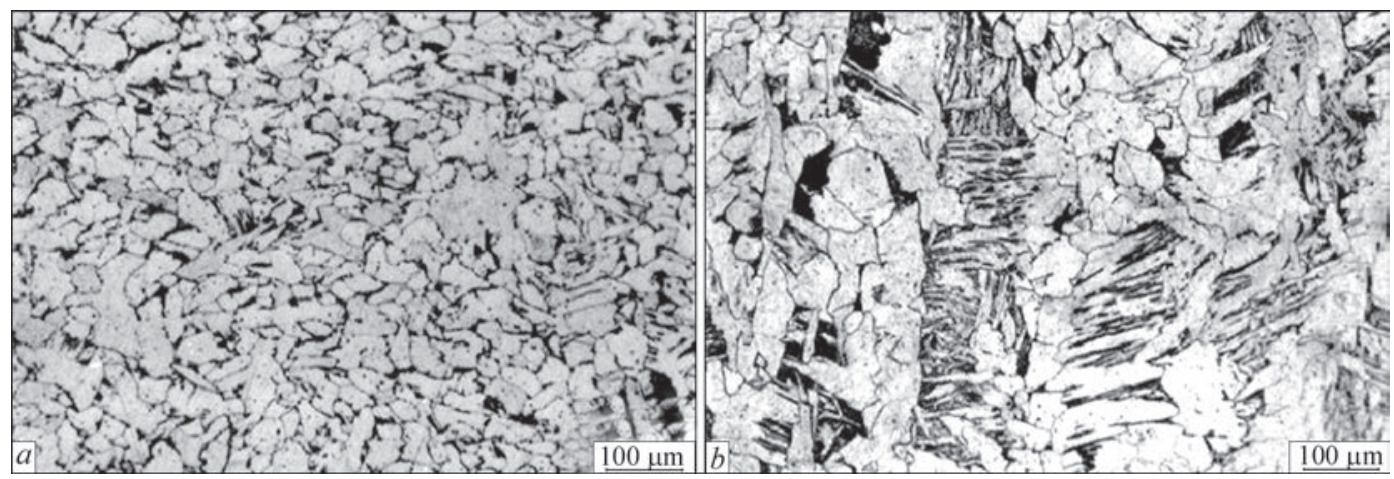

Figure 5. Macrostructure of product manufactured using method of electric arc additive surfacing in middle $(a)$ and top (b) of the product wall 


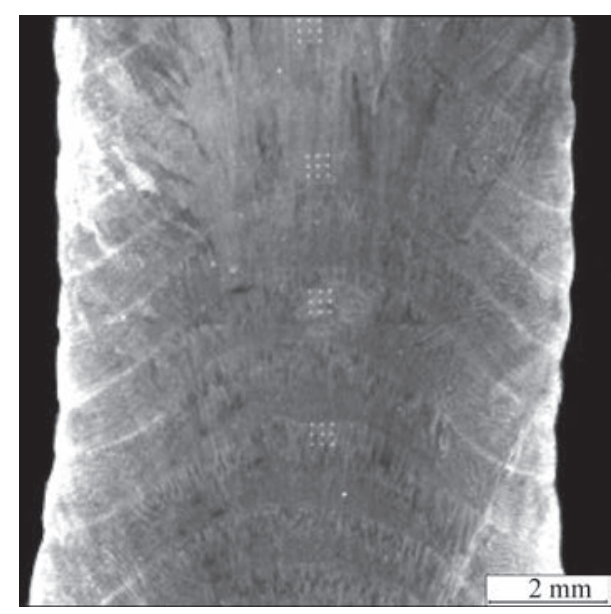

Figure 6. Macrostructure of cross-section of vertically deposited wall of steel 308593 using electric arc AM method

The results of measuring Vickers hardness (under $10 \mathrm{~kg}$ load) showed increase in values from the bottom to the top of the wall of the product from HV 146.3 to 172.6 respectively. This increase in hardness can be connected with tempering processes taking place when applying surfacing beads. Nevertheless, the study of microstructure showed that in $99.5 \%$ of the cases, the metal of specimens has a uniform, equiaxial ferrite-pearlite structure with grain size of about $60 \mu \mathrm{m}$ (Figure 5, a). However, for the local area limited by the last surfacing layer, the presence of dendritic grains size of approximately $600 \times 100 \mu \mathrm{m}$ is characteristic (Figure 5, $b$ ).

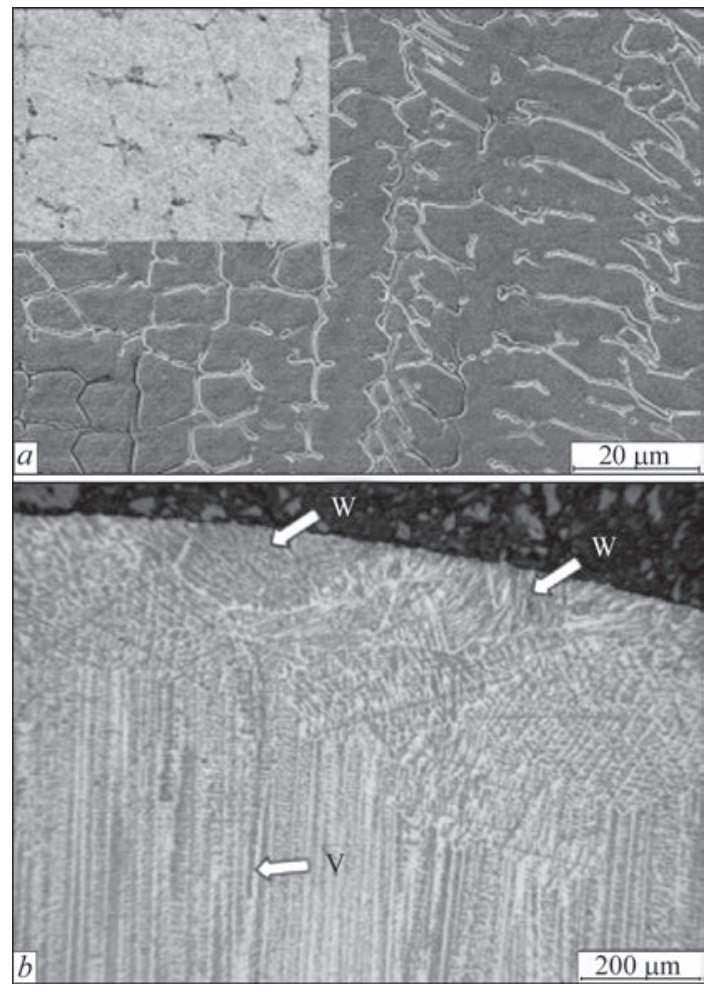

Figure 7. Microstructure of cross-section of weld of vertically electric arc AM-deposited wall of steel 308S93 in the middle $(a)$ and top $(b)$ of wall: V - lengthy acicular ferrite formations; W Widmanstaetten ferrite
The area of the last deposited layer does not undergo a repeated (and the subsequent cycles) heating as the previous layers do. With this fact the deterioration in relative elongation of specimens, cut from a wall top of the fabricated product, can be associated.

The researchers also note changes in geometry of the deposited layers with increase in height of the deposited metal.

The authors of work [19] carried out the similar investigations on austenitic stainless steel 308S93. Alongside a «box» with wall length of $130 \times 130 \mathrm{~mm}$, wall height of $31 \mathrm{~mm}$ grown in 30 welding passes and wall thickness of $8 \mathrm{~mm}$ was fabricated. The surfacing parameters were as follows: $2 \mathrm{~m} / \mathrm{min}$ wire consumption; 160 A welding current; $0.25 \mathrm{~m} / \mathrm{min}$ travel speed of welding head.

The results of investigations of macrostructure of the wall cross-section (Figure 6) showed the L-shaped deposited layers, repeating the weld reinforcement shape.

The microstructure of metal consists mainly of ferrite and austenite (Figure 7, $a$ ) in the form of disoriented equiaxial crystallites, whereas the structure in the area of the latter (upper) layer (Figure 7,b) consists of extended ferritic needles oriented in accordance with heat dissipation, and the areas of Widmanstaetten ferrite.

Average hardness value was $H V 186 \pm 15$ at $100 \mathrm{~g}$ load. The mechanical tests showed the average value of tensile strength of $537 \mathrm{MPa}$ at average relative elongation of $59 \%$. Also the researchers noted a tendency to deterioration of metal properties from the bottom to the top of the deposited wall.

In work [18] the results of investigations in the area of possibility of formation of different geometric elements of the created product are given. In particular, the selection of modes was carried out to create a horizontal ceiling wall (Figure 8,a). As a result the product with multidirectional planes without changes in inclination of priming plate during fabrication process was created (Figure $8, b$ ).

It should be noted that many researchers $[7,15$, $18,19]$, dealing with the problems of electric arc volumetric surfacing, focus their attention mainly on the questions of shaping. At the same time, some of them [6] carry out investigations in the field of accuracy of embodiment of the product shape and achievement of preset properties, such as influence of scanning parameters and geometric weld parameters on quality of the surface after deposition (Figure 9), or influence of residual stresses and deformations on the degree of accuracy of product fabrication by changing the program of scanning (Figure 10). 

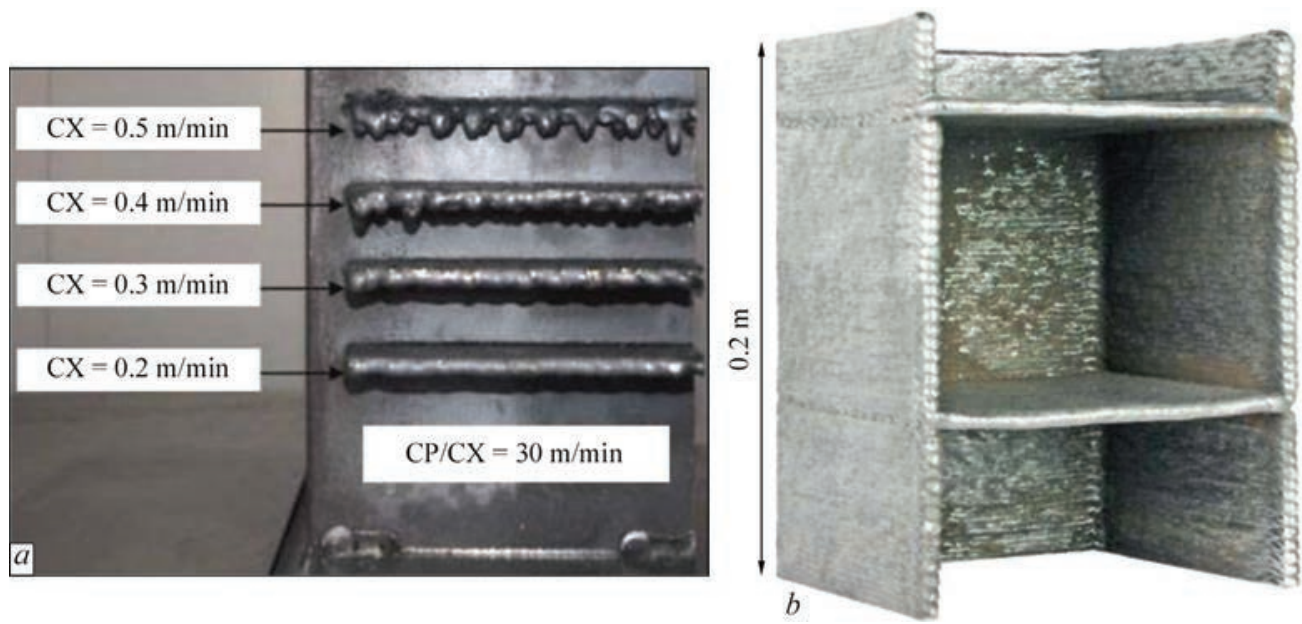

Figure 8. Selection of surfacing modes $(a)$ for creation of hinged horizontal surfaces $(b)$

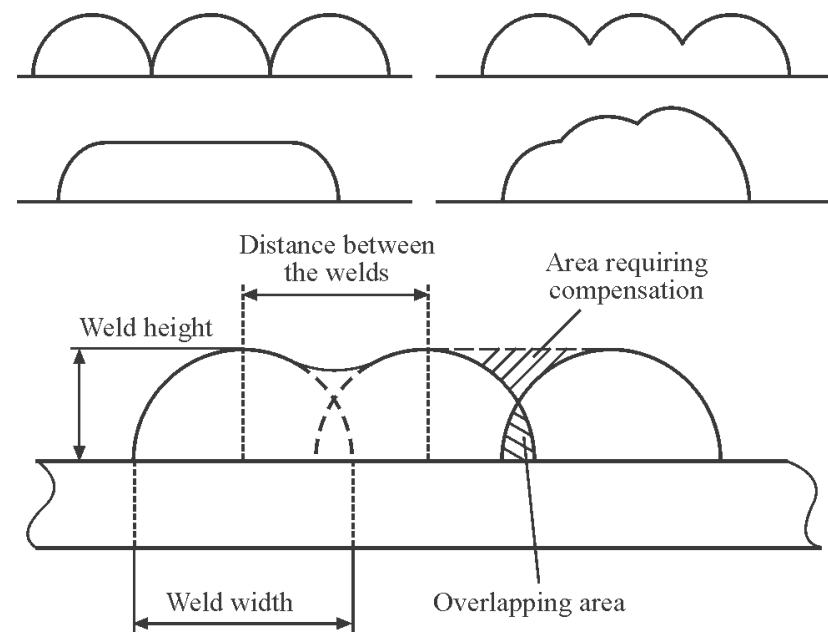

Figure 9. Peculiarities of weld geometry and influence of surfacing tool positioning on quality of the deposited surface

However, from the point of view of quality and reliability of metal product the primary feature is structure of metal rather than shape of the product. Although, in the case of metal products fabrication using spatial layer-by-layer surfacing the shape of the deposited weld is rigidly connected with the conditions of heat dissipation and, respectively, with the conditions of formation of inner structure of the metal, the primary task of metal product formation should remain a structural factor.

The approaches of structure control in the layer-by-layer ingot formation, developed at the E.O. Paton Electric Welding Institute [20], can be applied for creating metal products of complex geometric shape. The features of geometrical weld parameters formation depending on cooling conditions should be not a primary cause of the investigation, but a consequence and a technological feature, which should be taken into account, not trying to produce a uniform formation of layers, that is impossible under the condition of producing a uniform structure during fabrication of

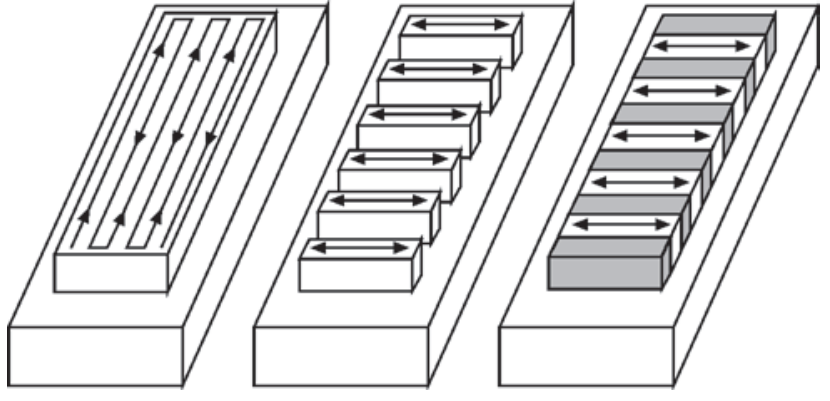

Figure 10. Variants of scanning movement of surfacing tool in process of creating the «wall» type element

complex product with the elements of different massiveness.

At the moment, at the PWI all the preconditions exist to create the technology of volumetric layer-by-layer electric arc automatic surfacing of volumetric metal products.

1. Wong, K.V., Hernandez, A. (2012) A review of additive manufacturing. Int. Scholarly Res. Network Mechanical Eng.; http://downloads.hindawi.com/journals/isrn/2012/208760.pdf

2. Rizwan, Ali P.M., Hara Theja, C.R., Syed Mahammad Syed Sheb et al. (2015) Review on diverse materials applied for additive manufacturing. Int. J. Res. in Applied Sci. \& Eng. Techn., Vol. 3, Issue VII, 16-20; http://www.ijraset.com/fileserve.php?FID=2945

3. Wohlers, T., Gornet, T. (2014) History of additive manufacturing: Wohlers Report. http://wohlersassociates.com/history2014.pdf

4. Guessasma, S., Zhang, W., Zhu, J. et al. (2016) Challenges of additive manufacturing technologies from an optimisation perspective. Int. J. Simulation and Multidisciplinary Design Optimization, 6; http://www.ijsmdo.org/articles/smdo/ pdf/2015/01/smdo150009.pdf

5. (2015) Quadrennial Technology Review. http://energy.gov/ sites/prod/files/2015/09/f26/Quadrennial-Technology-Review-2015_0.pdf

6. Ding, D., Pan, Z., Cuiuri, D. et al. (2015) Wire-feed additive manufacturing of metal components: Technologies, developments and future interests. Int. J. Advanced Manufac. Techn., 81(1-4), 465-481; http://www.researchgate.net/publication/275973182_Wire-feed_additive_manufacturing_of_met- 
al_components technologies_developments and future interests

7. Williams, S.W., Martina, F., Addison, A.C. et. al. (2015) Wire + arc additive manufacturing. Mater. Sci. and Techn.; http://www.researchgate.net/publication/277921887 WireArc_Additive_Manufacturing.

8. Frazier, W.E. (2014) Metal additive manufacturing: A review. J. Mater. Eng. and Perform., 23(6), 1917-1928; http://link. springer.com/article/10.1007/s11665-014-0958-z/fulltext. html

9. Simchi, A., Petzoldt, F., Pohl, H. (2003) On the development of direct metal laser sintering for rapid tooling. J. Materials Proc. Techn., 141, 319-328; http://www.ibrarian.net/navon/ paper/On the development_of direct_metal laser_sinterin. pdf?paperid $=21177098$

10. Kruth, J.P., Mercelis, P., van Vaerenbergh, J. et.al. (2004) Binding mechanisms in selective laser sintering and selective laser melting. In: Proc. of Solid Freeform Fabrication Symp. (Austin, USA), 44-59; http://sffsymposium.engr.utexas.edu/ Manuscripts/2004/2004-06-Kruth.pdf

11. Pal, D., Patil, N., Stucker, B.E. (2012) Prediction of mechanical properties of electron beam melted Ti6Al4V parts using dislocation density based crystal plasticity framework. In: Proc. of Solid Freeform Fabrication Symp. (Austin, USA), 37-43; http://sffsymposium.engr.utexas.edu/Manuscripts/2012/2012-40-Pal.pdf

12. Michaels, S., Sachs, E.M., Cima, M.J. (1992) Metal parts generation by three dimensional printing. In: Proc. of Solid Freeform Fabrication Symp. (Austin, USA), 244-250; http://sffsymposium.engr.utexas.edu/Manuscripts/1992/1992-28-Michaels.pdf

13. Atwood, C., Griffith, M., Harwell, L. et. al. (1998) Laser engineered net shaping (LENS ${ }^{\mathrm{TM}}$ ): A tool for direct fabrication of metal parts. In: Proc. of 17th Int. ALEO Congress (Orlando, USA), 16-19; http://digital.library.unt.edu/ark:/67531/ metadc621198/
14. Brandla, E., Baufeldb, B., Leyensc, C. et al. (2010) Additive manufactured Ti-6Al-4V using welding wire: Comparison of laser and arc beam deposition and evaluation with respect to aerospace material specifications. Laser Assisted Net Shape Eng., Vol. 5, Pt B, 595-606; http://www.sciencedirect.com/ science/article/pii/S1875389210005134

15. Dave, V.R., Matz, J.E., Eagar, T.W. (1995) Electron beam solid freeform fabrication of metal parts. In: Proc. of Solid Freeform Fabrication Symp. (Austin, USA), 64-70; http://sffsymposium.engr.utexas.edu/Manuscripts/1995/1995-09-Dave.pdf

16. Jandric, Z., Labudovic, M., Kovacevic, R. (2004) Effect of heat sink on microstructure of three dimensional parts built by welding-based deposition. Int. J. Machine Tools and Manufac., 44(7/8), 785-796; https://www.smu.edu/ /media/Site/ Lyle/RCAM/Publications/Effect \%20of \%20heat \%20sink $\% 20$ on \%20microstructure \%20of \%20three-dimensional. ashx

17. Friel, R.J., Harris, R.A. (2013) Ultrasonic additive manufacturing - A hybrid production process for novel functional products. In: Proc. of 7th CIRP Conf. on Electro Physical and Chemical Machining, Vol. 6, 35-40; http://www.sciencedirect.com/science/article/pii/S2212827113000784

18. Dickens, P.M., Pridham, M.S., Cobb, R.C. et al. (1992) Rapid prototyping using 3-D welding. In: Proc. of Solid Freeform Fabrication Symp. (Austin, USA), 280-290; http://sffsymposium.engr.utexas.edu/Manuscripts/1992/1992-32-Dickens. pdf

19. Skiba, T., Baufeld, B., van der Biest, O. (2009) Microstructure and mechanical properties of stainless steel component manufactured by shaped metal deposition. ISIJ Int., 49(10), 1588-1591; http://www.jstage.jst.go.jp/article/isijinternational/49/10/49_10_1588/pdf

20. Shapovalov, V.A. of solidification. Sovr. Elektrometallurgiya, 2, 51-54. 